\title{
Assessment of Knowledge and Quality of life for Patients Undergoing Cataract Surgery
}

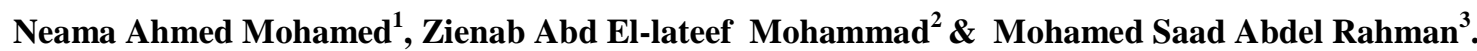 \\ Head nurse in Assiut University Hospital, Assuit University, Egypt. \\ Professor of Medical Surgical Nursing, Faculty of Nursing, Assuit University, Egypt. \\ Professor of Ophthalmology Faculty of Medicine, Assuit University, Egypt.
}

\begin{abstract}
Cataract is clouding in the natural lens of the eye. Aims: to assess knowledge and quality of life for patients undergoing cataract surgery. Patients and methods: sixty adult patients from males and females. This study carried in the ophthalmic department at Assiut university hospital. Research design: descriptive research design. Tools: two tools was used, Tool I: Patients interview questionnaire: contained three portions concerning, patient's demographic data, medical data and their knowledge regarding cataract. Tool II: The World Health Organization Quality of Life- BREF questionnaire. Results: (51.7\%) of patients were females (73.4\%) were illiterate, $48.3 \%$ were house wives and (41.7\%) their ages were between (60-65) years of age. The majority of participations (98.4\%) had incorrect information about cataract. (73.4\%) of participations had poor quality of life. Conclusion; majority of participations had insufficient information about cataract which influenced negatively on the quality of life of more then two thirds of the studied patients. Recommendations: Suggested nursing teaching program for patients undergoing cataract surgery based on their needs is recommended to improve their knowledge and quality of life.
\end{abstract}

\section{Keywords: Cataract Surgery, Knowledge \& Quality of Life.}

\section{Introduction}

Cataract is a visual disease that is characterized by increasing opacity of the lens resulting in visual impairment. Frequency of cataract increases with age which leads to loss of sight and visual deficiency in elderly populations in developing nations (Mario \& Angel, 2017)

Cataracts affect nearly 22 million Americans aged 40 and older, about partial of all 65-year-old Americans are suffering from some grade of cataract development. Cataracts worsen the effects of agerelated problems by decreasing the capability to see in dark conditions. (Stroud \& Walker, 2012)

Aging is the most common causes; Age related cataract progresses in two ways a clump of protein reduces the sharpness of the mage reaching the retina. Lens proteins denature and damage over time also this progression is quickened through illnesses for example diabetes and hypertension. And the pure lens is reducing alterations toward a yellowish /brownish color, the color lens gradually alterations color with age. (Aldwin \& Gilmer, 2013)

Systemic disease (such as diabetes); high levels of blood sugar cause the lens of the eye to swell with excess fluid, making diabetic patients added vulnerable to cataracts, heredity, medications for example corticosteroids especially at high doses and in long-term use, arthritis.(Bruno et al., 2013)

In the early stages of a cataract, where vision is only minimally affected, unused lenses for glasses grant the most honed vision conceivable. When the cataracts start to interfere with adult's daily activities
(ADL) and glasses cannot improve this vision, surgery is the single choice to remove the natural lens and change the lens and using a new, artificial one. It is the foremost secure and most popular techniques done, but this is not equally available to all, and the operation which is available does not create equal outcomes. (Charles et al., 2015)

Cataract surgery is done with local anesthesia or general anesthesia which ordinarily takes less than 1 hour. It includes insertion a local anesthesia (eye drops) on the cornea and conjunctiva. Commonly used local anesthesia includes Lidocain $2 \%$ jell, proparacain $0.5 \%$ and tetracaine $0.75 \%$. (Anne \& Jane, 2010) Vision problems due to cataract have some negative effect on studied patients' (Qol). (Navarro et al., 2016)

Impaired vision can effects on doings of everyday living, such as washing, wearing, cooking, reading, watching television and even walking. More significantly, people who cannot detect ground-level hazards, such as steps, kerbs and pavement cracks, are more probable to fall and sustain injuries, such as a hip fracture. Reduced sharing in social activities, meanwhile, may cause a sense of isolation and loneliness, and even the gradual onset of depression (Watkinson, 2011).

Several patients with visual diminishing such as cataract experience depression, which affects their Qol (Williamson \& Seewoodhary, 2013). This condition should not be underestimated and nurses ought to capable to identify its core symptoms, which include persistent sadness, fatigue and anhedonic (loss of pleasure). Other associated symptoms include 
disturbance of sleep and appetite, poor concentration, agitation, low self-confidence, suicidal thoughts and/or acts; however, patients may not complain of sadness and are more probable to refer to physical symptoms (WHO, 2011)

Impaired vision affects a person's independence in self-care, work and way of life choices, and sense of self-esteem, security, and capacity to associated with society. Patients can develop more hopeful given more information also well understanding of what it involves, and how it can help to promote a better Qol (Watkinson, 2011).

Patients with cataract have many physical, social, and emotional problems that affect their dependence in self-care and performance of daily living activities, which consequently affect quality of life (QOL) activities. According to statistical report at Assiut university hospital, the number of patients undergoing cataract surgery was approximately (542) in 2016-2017. Nurses play an important role in all aspects of cataract surgery. The challenges are to prevent or delay the occurrence of problems, and promptly manage any which does occur.

\section{Aim of the study}

To assess knowledge and quality of life for patients undergoing cataract surgery.

\section{Patients and Methods}

Research design: descriptive research design.

Technical design

Setting: ophthalmic department at Assiut university hospital.

\section{Patients}

60 adult patients from both gender their age ranged from (18-65) years. Patients were admitted in ophthalmic department for cataract surgery.

\section{Tools}

Tool I: Patients Interview Questionnaire: It covered three portions:

Part one: Demographic data about the patients: it contained age, sex, level of education, \& occupation.

Part two: Medical data included: duration of cataract, previous eye surgery, and risk factors for example chronic disease (diabetes mellitus, hypertension, and cardiovascular disease), smoking and family history.

Part three: Patients' knowledge regarding cataract included; Definition of cataract, causes, risk factors, signs \& symptoms, complications of cataract and preoperative and postoperative care, instilling eye drops, ointment application, changing eye dressing, performing eye care and prevent infection of the eye.

\section{Scoring system}

Every correct answer in the part three was given two degrees. The overall score (grade 70), these scores were converted into a percent score, the results of patient were classified into three categories (50\%) was poor knowledge, (50 70\%) was fair knowledge and $(\geq 70 \%)$ was good knowledge.

Tool II: The World Health Organization Quality of Life- BREF questionnaire (WHOQOL-BREF): (Bonomi and Patrick., 1997): It involved 26 objects, related to four domains: physical health ( 7 items), spiritual health (6 items), social interactions (3 items), and environment (8 items). Two extra items measured overall QOL and general health. Items are evaluated on a 5-point Likert scale (low score of 1 to high score of 5) to define a raw item score.

Scoring system

According to range of total scores lie between (26 130), patients were ordered as: good, fair or poor quality of life. Good quality of life in case their whole score was $\geq 70 \%$, fair $50<70 \%$ at that point were considered as taking poor quality of life in the event that their total score was $<50 \%$.

\section{Operational design}

\section{Preparatory stages}

- In this stage, the tools designed for statistics collection after checking on the related writings were developed. Validity of tools was completed by 5 experts.

- By the termination of this stage, a pilot study was passed out on $10 \%$ of participations to test the plausibility of the study and appropriateness of the tools and the period requisite to finish for statistics collection. Minor changes were done appropriately.

Implementation stages

- An official endorsement for statistics collection was developed from the head of authorized organization in ophthalmic department at Assuit university hospital just before conduct the study

- Obtained verbal agreement for voluntary participation was taken from the patients after aims were explained.

\section{Techniques for data collection:}

Data were collected from ophthalmic department at Assiut university hospital during the period from July/2016 to May/2017. At initial interview the researcher introduce her self to initiate line of communication. The tools (I and II) filled through interviewing. The purpose of the study was explained to the patients prior to answering the questions. There was not exactly detectable length of time of the interview, because patients are different in their ability of understanding.

Ethical considerations

1. Research proposal was approved from Ethical Committee in the faculty of nursing.

2. There was no risk for study subjects during application of the research.

3. The study followed common ethical principles in clinical research. 
4. Written consent was obtained from patient's who participated in the study, after explaining the nature and purpose the study.

5. Confidentiality and anonymity was assured.

6. Study subject had the right to refuse to participate and or withdraw from the study without any rational any time.

7. Study subject privacy was considered during collection of data.

\section{Statistical design}

The statistical analysis was passed out by SPSS. Descriptive statistics (frequencies and percentages, mean and standard deviation, i.e.) Independent sample $\mathrm{T}$ test, Chi-square and One-way-anova tests used in relationship between participation on knowledge and quality of life

\section{Results}

Table (1): Distribution of the studied patients according to demographic characteristics $(\mathbf{n}=60)$.

\begin{tabular}{|c|c|c|}
\hline Items & N. & $\%$ \\
\hline \multicolumn{3}{|l|}{ Age groups } \\
\hline $18<40$ years & 13 & 21.6 \\
\hline $40<60$ years & 22 & 36.7 \\
\hline $60-65$ years & 25 & 41.7 \\
\hline \multicolumn{3}{|l|}{ Sex } \\
\hline Male & 29 & 48.3 \\
\hline Female & 31 & 51.7 \\
\hline \multicolumn{3}{|l|}{ Marital status } \\
\hline Single & 4 & 6.7 \\
\hline Married & 48 & 80 \\
\hline Divorced & 0 & 0 \\
\hline Widow/er & 8 & 13.3 \\
\hline \multicolumn{3}{|l|}{ Level of education } \\
\hline Illiterate & 44 & 73.4 \\
\hline Read and write & 6 & 10 \\
\hline Primary school & 5 & 8.3 \\
\hline Secondary education & 5 & 8.3 \\
\hline High education & 0 & 0 \\
\hline \multicolumn{3}{|l|}{ Occupation } \\
\hline Worker & 9 & 15 \\
\hline Farmer & 12 & 20 \\
\hline House wife & 29 & 48.3 \\
\hline Manual work & 4 & 6.7 \\
\hline Not working & 6 & 10 \\
\hline
\end{tabular}

Table (2): Distribution of the studied sample regarding their medical data

\begin{tabular}{|l|c|c|c|c|}
\hline \multicolumn{1}{|c|}{ Items } & N. & \% & N. & \% \\
\hline 1-Duration of cataract. & Yes. & \% & No. & \% \\
\hline one month & 8 & 13.3 & - & - \\
\hline Two months & 9 & 15 & - & - \\
\hline Three months & 14 & 23.4 & - & - \\
\hline More than three months & 29 & 48.3 & - & - \\
\hline 2-Previous eye surgery. & 22 & 36.6 & 38 & 63.4 \\
\hline $\begin{array}{l}\text { 3-Risk factors. } \\
\bullet \text { Chronic diseases. }\end{array}$ & & \multicolumn{3}{|c|}{} \\
\hline -Diabetes & 7 & 11.6 & 53 & 88.4 \\
\hline -Hypertension & 7 & 11.6 & 53 & 88.4 \\
\hline -Heart disease & 2 & 3.3 & 58 & 96.7 \\
\hline - Smoking & 10 & 16.6 & 50 & 83.4 \\
\hline Family history & 18 & 30 & 42 & 70 \\
\hline
\end{tabular}




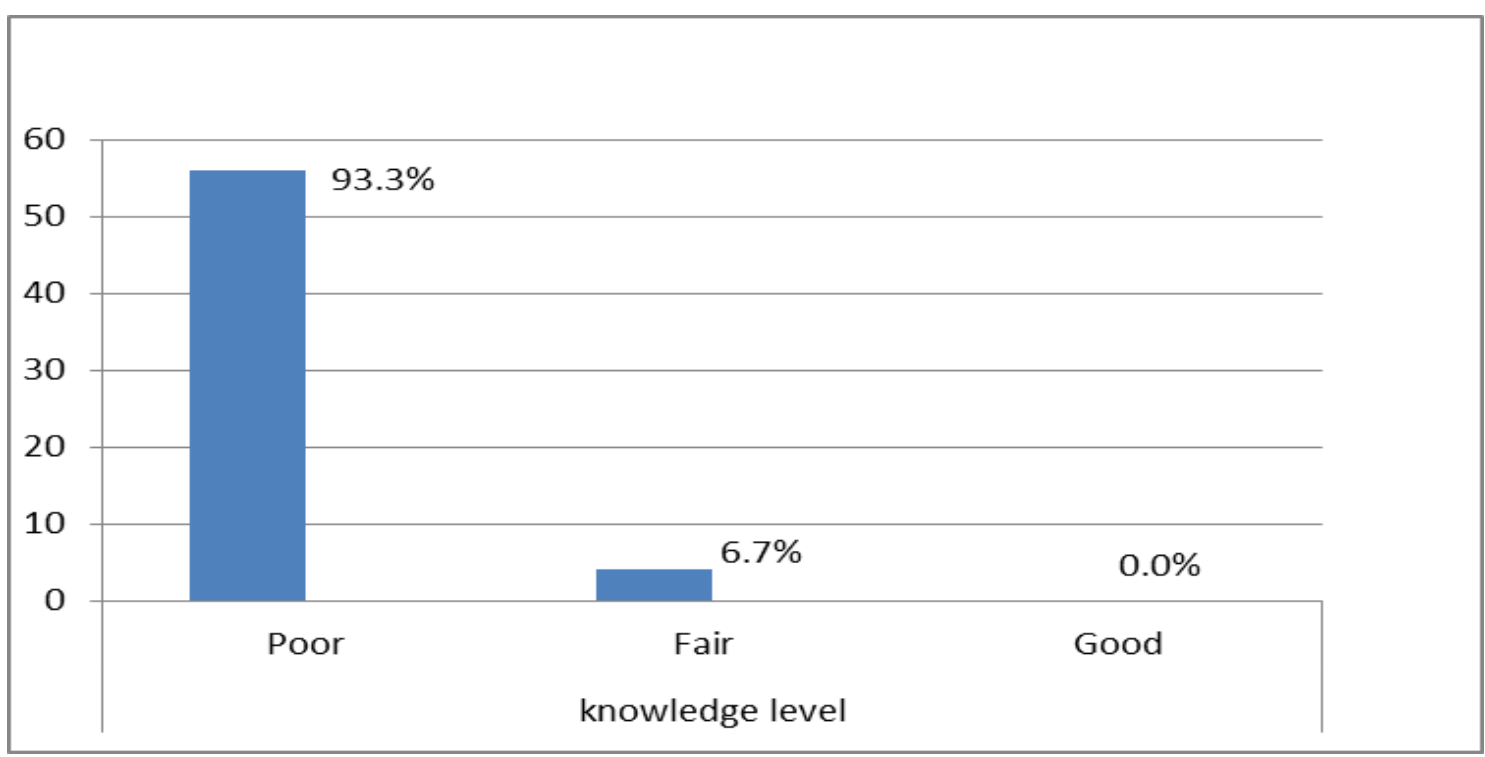

Figure (1): Distribution of the participations regarding to their level of knowledge about cataract

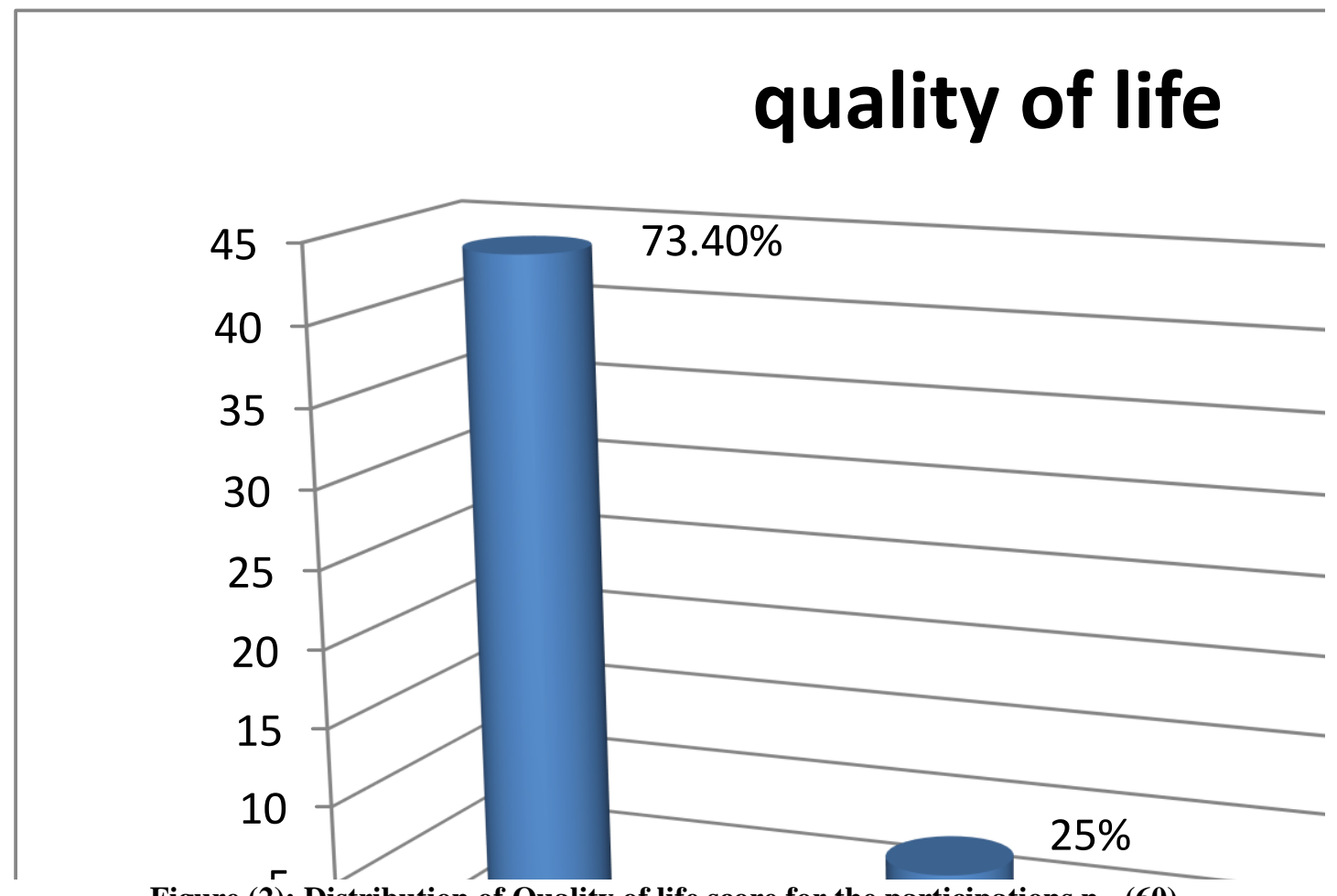

Figure (2): Distribution of Quality of life score for the participations $n=(60)$ 
Table (3): Relation between demographic characteristics and level of knowledge $(n=60)$.

\begin{tabular}{|c|c|c|c|c|c|}
\hline \multirow{3}{*}{ Items } & \multicolumn{4}{|c|}{ knowledge } & \multirow{3}{*}{ P. value } \\
\hline & \multicolumn{2}{|c|}{ Poor } & \multicolumn{2}{|c|}{ Fair } & \\
\hline & N. & $\%$ & N. & $\%$ & \\
\hline \multicolumn{5}{|l|}{ Gender: } & \multirow{3}{*}{$0.100 \mathrm{n} . \mathrm{s}$} \\
\hline Male & 23 & 38.4 & 6 & 10 & \\
\hline Female & 29 & 48.3 & 2 & 3.3 & \\
\hline \multicolumn{5}{|l|}{ Age: } & \multirow{4}{*}{0.196 n.s } \\
\hline $18<40$ & 12 & 20 & 1 & 1.6 & \\
\hline $40<60$ & 19 & 31.7 & 3 & 5 & \\
\hline $60-65$ years & 21 & 35 & 4 & 6.7 & \\
\hline \multicolumn{5}{|l|}{ Marital status } & \multirow{5}{*}{$0.400 \mathrm{n} . \mathrm{s}$} \\
\hline Single & 4 & 6.7 & 0 & 0.0 & \\
\hline Married & 40 & 66.7 & 8 & 13.3 & \\
\hline Divorced & 0 & 0.0 & 0 & 0.0 & \\
\hline Widowed & 8 & 13.3 & 0 & 0.0 & \\
\hline \multicolumn{5}{|l|}{ Level of education } & \multirow{6}{*}{$0.431 \mathrm{n} . \mathrm{s}$} \\
\hline Illiterate & 37 & 61.7 & 7 & 11.8 & \\
\hline Read and write & 5 & 8.3 & 1 & 1.6 & \\
\hline Primary education & 5 & 8.3 & 0 & 0.0 & \\
\hline Secondary education & 5 & 8.3 & 0 & 0.0 & \\
\hline High education & 0 & 0.0 & 0 & 0.0 & \\
\hline \multicolumn{5}{|l|}{ Occupation } & \multirow{6}{*}{0.278 n.s } \\
\hline Employee & 9 & 15 & 0 & 0.0 & \\
\hline Farmer & 8 & 13.3 & 4 & 6.7 & \\
\hline Manual work & 4 & 6.7 & 0 & 0.0 & \\
\hline House wife & 27 & 45 & 2 & 3.3 & \\
\hline No work & 4 & 6.7 & 2 & 3.3 & \\
\hline
\end{tabular}

$n . s=$ Not significant $(P>0.05)$

Table (4): Relation among knowledge \& quality of life.

\begin{tabular}{|c|c|c|c|c|c|c|c|}
\hline \multicolumn{7}{|c|}{ quality of life $\mathbf{n =}(\mathbf{6 0})$} \\
\hline \multirow{3}{*}{ knowledge level } & \multicolumn{2}{|c|}{ Faire } & \multicolumn{3}{|c|}{ Good } & P value \\
\cline { 2 - 8 } & N. & \%oor & N. & \% & N. & \% & \multirow{2}{*}{$0.00 *$} \\
\cline { 2 - 8 } & 44 & 58.4 & 15 & 15 & 1 & 0.0 & \\
\hline
\end{tabular}

Chi-Square Test $\quad *$ Statistical significant differences $(p \leq 0.05)$

Table (5): Relation between educational level \& quality of life $n=(60)$.

\begin{tabular}{|c|c|c|c|c|c|c|c|}
\hline \multirow{3}{*}{ Items } & \multicolumn{6}{|c|}{ quality of life $n=(60)$} & \multirow[b]{2}{*}{ P value } \\
\hline & \multicolumn{2}{|c|}{ Poor } & \multicolumn{2}{|c|}{ Faire } & \multicolumn{2}{|c|}{ Good } & \\
\hline & $\mathbf{N}$. & $\%$ & $\mathbf{N}$. & $\%$ & N. & $\%$ & \\
\hline Illiterate & 35 & 58.4 & 9 & 15 & 0 & 0.0 & \\
\hline Read and write & 4 & 6.7 & 1 & 1.6 & 1 & 1.6 & $0.007 *$ \\
\hline primary school & 1 & 1.6 & 4 & 6.7 & 0 & 0.0 & \\
\hline Secondary school & 4 & 6.7 & 1 & 1.6 & 0 & 0.0 & \\
\hline
\end{tabular}

Chi-Square Tests

* Statistical significant differences $(p \leq 0.05)$ 
Table (1): Revealed that, (41.7\%) of patient's age run among $(60-65)$ years old. Regarding sex $(51.7 \%)$ of the studied patients were females. Regarding marital status, (80\%) were married. As regard to occupation the majority of participation were house wives and illiterate.

Table (2): Expressed that, (26.7\%) of studied patients had chronic disease \{diabetes mellitus, hypertension (11.6\%) and heart disease (3.3\%)\}. Smoking $(16.6 \%)$ and the majority of studied patients were family history $(30 \%)$.

Table (3): Cleared up that, no statistical difference was found between patients' knowledge about cataract \& their demographic characteristics $\mathrm{P}>0.05$.

Table (4): Displayed that, (58.4\%) of participation had poor quality of life \&level of knowledge. There is statistical significant relation between patients Qol $\&$ their knowledge level.

Table (5): Illuminated that, there is statistical significant relation between patients' educational level \& Qol P $<0.001$

Figure (1): Demonstrated that, (93.3\%) of the participation had poor knowledge score.

Figure (2): Indicated that, high percentage (73.4\%) of the studied patients had poor quality of life.

\section{Discussion}

Cataract is defined as cloudiness or loss in transparency in the lens of the eye. When a cataract interferes with transmission of light to the retina, some loss in visual acuity and possible complete damage of vision may result. (Moini, 2015)

Visual impair Qol ment is devastating for patients, it has negative effects on health-related Qol, it is associated with restrictions in mobility, doings of everyday living also physical performance. (Michalos et al., 2012)

In the present study, findings regarding demographic characteristics revealed that, patients' ages were between 60 - 65 years old; this might be the effect of cataract on old age. This is in agreement with Pundareekaksha (2016) who found the same result. Regarding marital status, the present study clarified that, more than half of the participation are females; this outcome is in disagreement with Pundareekaksha (2016) who found that more than half of the samples are males. This result is in agreement with Mary et al., (2015) \& Athiya et al. (2011) who found that the larger part of participation were married; the highest percentage was house wives and illiterate.

As regards to educational level, the results of the recent study denoted that, the highest percentages were illiterate, this may well be due to most of participation were females and were house wifes. This finding is agreed with (Duker \& Yanoff, 2013) who reported that, level education is associated with risk factors of cataract for examples smoking, alcohol intake and increased sun exposure in individuals with moo little education. In contrast, it disagrees with

Hegazy et al., (2012) who represented that highly educated are more likely to have cataract surgery.

The present study points to that studied patients had chronic illness, diabetes mellitus and hypertension and family history. This result agreed with Timby $\boldsymbol{\&}$ Smith (2013) who stated that a high incidence of cataracts occurs among people with diabetes and those with a family history. It can moreover be backed by Duker \& Yanoff (2013) who stated that, Diabetes mellitus and systemic hypertension are common in the population predisposed to operable cataract formation and these conditions may adversely influence of the surgery. This consequence is in agreement with Solberg, et al., (2016) who found that cataract causes severe visual diminishing and loss of sight, are directly accelerated by smoking and meaningfully associated to this harmful habit.

The current study revealed that; the high percentage of participation had insufficient information of cataract. This could be described by the fact that, participation didn't obtain sufficient knowledge from health care group and the most of the participation were illiterate.

As concerns to Qol the recent study revealed that, the most elevated rate of participation had poor Qol. This result is agreement with Elfride et al., (2016) who state the same result. On the other hand, this result is in contradiction by Abraham et al., (2016) who found that the most elevated rate of participation good On the other hand, this result is in contradiction by Abraham et al., (2016) who found that the most elevated rate of participation were having good Qol. Regarding relation between knowledge level and Qol, the highest percentage of participation who had poor knowledge \& Qol. This result differs with Abraham et al., (2016) who signified that, there's no significant relationship between the knowledge and Qol regarding Benign Prostatic Hyperplasia. This consequence is in agreement with Shah \& Pokharel (2013) who found that there is positive relationship between the information and Qol.

The present study indicated that; most of studied patients who were illiterate had poor Qol with statically significant relation. This result is in contract with (Zibadi et al., 2013) who informed that, high level of education is associated with lower risk of cataract due to awareness about causative factors. Ignorant or individuals with slight education are insensible approximately the dangerous impacts of tobacco utilization, smoking, liquor abuse, sunlight and less vitamins supplement intake. Also, this outcome is in agreement with Barbareschi et al., 
(2011) who reported that, patients with low educational levels had the worst quality of life.

\section{Conclusion}

The majority of the studied patients had deficient knowledge about cataract which had negative effect on the quality of life of more than two thirds of them.

\section{Recommendation}

1. Suggested nursing teaching program for patients undergoing cataract surgery based on their needs is recommended to improve their knowledge and quality of life.

2. Informants the patients significance of follow up to prevent developing any complications after cataract surgery which can affect on the quality of life.

\section{References}

1. Abraham P., Sequira L., \& Nayak S., (2016): A Study to assess the knowledge and quality of life of patients with Benign Prostatic Hyperplasia $(\mathrm{BPH})$, International Education and Research Journal, Volume 6, Issue 2, PP21-22

2. Aldwin C., \& Gilmer D., (2013): Health and illness and optimal aging ch7, Aging of the sensory and Nervous Systems, Springer Publishing Company, p.395.

3. Anne L., \& Jane N., (2010): Foundations of Low Vision: Clinical and Functional Perspectives.ch 6 Causes of Visual Impairment: Pathology and Its Implications, American Foundation for the Blind, p.154.

4. Athiya A., Agarwal A., \& Jacob S., (2011): Phacoemulsification.ch1, Cataract Etiology, JP Medical Ltd, P.6.

5. Barbareschi G., Sanderman R., Leegte I., van Veldhuisen D., \& Jaarsma T., (2011): Educational level and the quality of life of heart failure patients: a longitudinal study. Journal of cardiac failure, Volume (1):47-53.

6. Bonomi A., \& Patrick D., (1997): User's manual and interpretation guide for the United States version of the World Health Organization Quality of Life (WHOQOL) instruments. Seattle (WA): U.S. WHOQOL Center.

7. Bruno V., Debbie T. and Joseph O., (2013): Nursing Home Care.ch1, Long Term Care Needs in an Aging World, McGraw Hill Professional, p.6.

8. Charles N., Margaret E., Dean T., Atul G., Peter D., \& Haile T., (2015): Essential Surgery: Disease Control Priorities, $3^{\text {rd }}$ edition, (Volume 1), ch 3, Surgery and Trauma Care, World Bank Publications, P.199.
9. Duker J., \& Yanoff M., (2013): Expert Consult: Online and Print: Ophthalmology, ch 5, The Lens, Elsevier Health Sciences, P. 413.

10. Elfride F., Philip S., \& Kishore S., (2016): Knowledge, attitude, practice and quality of life assessment in glaucoma- a cross sectional survey, nternational Journal of Medical Research and Review, 4(12):2199-2204.

11. Hegazy S., Ragheb M., Elsayed N., \& Rashad M., (2012): Health Needs Managements Among Patients Undergoing Day Case Cataract Surgery. Proposed protocol,life science Journal; 9(2): 13161327. Available at:http://www.lifesciencesite.com

12. Mario D., \& Angel C., (2017): Impact of Lipid Peroxidation on the Physiology and Pathophysiology of Cell Membranes, Ch1, Lipid Peroxidation: Pathophysiology and pharmacology implications in the eye, Frontiers Media SA, P.9.

13. Mary B., Fang L., \& Kushalan K., (2015): A Study To Assess The Knowledge On PostOperative Self-Care Activities Among Patients Who Have Undergone Cataract Surgery At A Selected Hospital, Malaysia, Journal of Health, Medicine and Nursing, Vol. 13 .

14. Michalos A., Sirgy J., \& Kenneth C., (2012): Handbook of Social Indicators and Quality of Life Research, Ch 20, Economies in Transition: Revisiting Challenges to quality of life, Springer Science \& Business Media P.414.

15. Moini J., (2015): Fundamental Pharmacology for Pharmacy Technicians, 2th edition, Ch 27 Drug therapy for Geriatric patients, Cengage learning P.545.

16. Navarro N., Pol E., \& Fleury-Bahi G., (2016): Handbook of Environmental Psychology and Quality of Life Research, ch29, Emerging Risk and Quality of life New Dimensions of wellBeing? P.539.

17. Pundareekaksha R., (2016): A study to assess the knowledge of patients regarding post cataract surgical care and complications, International Journal of Medicine Research, Volume 1; Issue 2; Page No. 97-100.

18. Shah S., \& Pokharel N., (2013): Knowledge Regarding Self Care Measures and Quality of Life among Patients with Chronic Renal Failure undergoing Hemodialysis, Original Research Article, Volume 1, No 1, PP 39-42

19. Solberg Y., Rosner M., \& Belkin M., (2016): The Association between Cigarette Smoking and Ocular Diseases, Article Survey of Ophthalmology, Volume (6):535-47 
20. Stroud D., \& Walker K., (2012): Marketing to the Ageing Consumer: The Secrets to Building an Age-Friendly Business, ch5, The Aging Senses, Palgrave Macmillan Britain, p.63.

21. Timby K., \& Smith E., (2013): Introductory Medical-Surgical Nursing. $11^{\text {th }}$ ed Ch41, Caring for Clients with Sensory Disorders, Lippincott Williams \& Wilkins, P.678.

22. Watkinson S., (2011): Managing depression in older people with visual impairment, ch1, Nursing Older People Pp.8, 23.

23. Williamson S., \& Seewoodhary R., (2013): Cataract blindness in older people and sight restoration: a reflection. International Journal of Ophthalmic Practice, Pp. 4, 5, 212-218.

24. World Health Organization (WHO) (2011): Depression www.who.int/topics/ depression/en (Last accessed: December 22 2014.)

25. Zibadi S., Victor R., \& Watson R., (2013): Alcohol, Nutrition, and Health Consequences, ch5, Alcohol and chronic disease, Springer Science \& Business Media P.31 